\title{
To Stamp Out "So Terrible a Malady": Bovine Tuberculosis and Tuberculin Testing in Britain, 1890-1939
}

\author{
KEIR WADDINGTON*
}

In the early-twentieth century, moves to prevent infection from tuberculosis became an integral part of local government public health schemes. ${ }^{1}$ While the scale of action was dependent on individual authorities and ratepayers, interest was not limited to the pulmonary form of the disease. Effort was also directed at tackling bovine tuberculosis, which by the 1890s had become "the most important disease of cows" and, with its zoonotic properties accepted, "a substantial risk to the .. . consumer". ${ }^{2}$ With meat and milk identified as the main vectors, moves to detect infected livestock and limit the spread of the disease became part of a wider preventive strategy. Measures were introduced to control the sale of tuberculous meat and milk. Eradication schemes were promoted, as concern merged with a growing interest in food safety and agriculture, and became caught up with debates on national efficiency, farming and child health.

Local and national attempts to limit infection from bovine tuberculosis were fuelled by fears about the prevalence of the disease in cattle. A transition in the nature of agriculture, with a shift from arable to livestock and dairy farming, combined with farmers' apparent unwillingness to stamp out bovine tuberculosis, ensured that levels of infection remained high until the 1950s. Estimates of the number of tuberculous cattle ranged from 25 to 40 per cent of the national herd, though even the latter figure was considered too conservative by some contemporaries. ${ }^{3}$ The prevalence of the disease in cattle was correlated with levels of non-pulmonary tuberculosis in the human population. Rough calculations from mortality returns placed the annual death rate from bovine tuberculosis at 3,000, with a larger number crippled. Although this represented 5 to 6 per cent of the annual mortality from all forms of tuberculosis, children were believed to be at greater risk as susceptibility diminished with age. ${ }^{4}$ That mortality from the disease remained stable, despite a fall in cases of nonpulmonary tuberculosis, only heightened alarm. The problem had a wider dimension

* Keir Waddington, PhD, School of History and Archaeology, Cardiff University, PO Box 909, Cardiff, CF10 3XU, UK.

${ }^{1}$ See F B Smith, The retreat of tuberculosis 1850 1950, London, Croom Helm, 1988; Linda Bryder, Below the magic mountain: a social history of tuberculosis in twentieth-century Britain, Oxford, Clarendon Press, 1988.

${ }^{2}$ William Savage, Milk and the public health, London, Macmillan, 1912, p. 125.

${ }^{3}$ People's League of Health, Report of a special committee appointed by the People's League of Health to make a survey of tuberculosis of bovine origin in Great Britain, London,

People's League of Health, 1932, pp. 1-9; H Hyslop

Thomson, Tuberculosis and national health,

London, Methuen, 1939, p. 109; Br. med. J., 1924, i: 347 .

${ }^{4}$ Ministry of Health, A memorandum on bovine tuberculosis in man with special reference to infection by milk, Reports on Public Health and Medical Subjects, London, 1931, p. 23; London Metropolitan Archive: 'Non-pulmonary tuberculosis decline in London', LCC/PH/GEN/4/239. 


\section{Keir Waddington}

because bovine tuberculosis also jeopardized the financial health of an already precarious farming industry. Tuberculous cattle "cost the country vast sums yearly in compensation, and the agricultural industry very large amounts in depreciation" at a time when dairy farming was becoming "the principal source of farm income". Here was serious cause for concern. For Peter Koolmees, "As it became clear that tuberculosis caused serious human illness as well as a loss of animal production, attempts were made to eradicate this zoonosis". 6

This combination of public health and agriculture concerns shaped responses to bovine tuberculosis. Interest in the disease throughout the interwar years remained, according to Eastwood at the Ministry of Health, "partly medical, partly veterinary, partly agricultural, largely economic, and very closely knit together". 7 For the public health lobby, "the eradication of bovine tuberculosis necessarily entails a large reduction in the prevalence of one of the most fatal diseases of childhood". ${ }^{8}$ For farmers and the Ministry of Agriculture and Fisheries (MAF) there were important economic considerations at the time when the state was becoming ever more involved in the regulation of food production and sale. However, as one American observer noted:

while we can safeguard to some degree the health of the consumer by cooking the flesh of animals and pasteurizing dairy products, still such practices do not strike at the real evil. They deal with the effect and not the cause ... A systematic attack should be made on the source. ${ }^{9}$

It was this concern for "the source" that focused action in the first half of the twentieth century. Efforts were made to increase resistance among cattle through breeding and improved stable hygiene, and research was conducted into developing a vaccine. Greater attention was devoted to improving the quality and safety of milk. While the science of pasteurization was contested, measures to identify tuberculous cattle and promote diseasefree herds proved less controversial. ${ }^{10}$ At the centre of these attempts to identify, label and stamp out bovine tuberculosis was tuberculin.

The synthesis of tuberculin had been announced as a breakthrough in the cure of tuberculosis in 1890 by the pioneering bacteriologist, Robert Koch. Enthusiasm quickly soured once it became clear that tuberculin was not the effective cure Koch had claimed. ${ }^{11}$ However, evidence that it was a valuable diagnostic agent gave it a new role in both human and animal health. By the 1930s, tuberculin testing had emerged as the first line of defence in

\footnotetext{
${ }^{5}$ Leslie Jordan, The eradication of bovine tuberculosis, London, HMSO, 1933, p. 3.

${ }^{6}$ Peter Koolmees, 'Veterinary inspection and food hygiene in the twentieth century', in David F Smith and Jim Phillips (eds), Food, science, policy and regulation in the twentieth century: international and comparative perspectives, London, Routledge, 2000, p. 61.

${ }^{7}$ Public Record Office (PRO): Eastwood to W Fletcher, 25 April 1922, FD 1/154.

${ }^{8}$ Harold Scurfield, 'Use of tuberculin', Public Health, 1899, 12: 39.

${ }^{9}$ J F De Vine, Bovine tuberculosis, Chicago, American Veterinary Publishing, 1917, p. 31.
}

\footnotetext{
${ }^{10}$ See Peter Atkins, 'The pasteurisation of England. The science, culture and health implications of milk processing, 1900-50', in Smith and Phillips (eds), op. cit., note 6 above, pp. 37-51; Jim Phillips and Michael French, 'State regulation and the hazards of milk, 1900-1939', Soc. Hist. Med., 1999, 12: 371-88.

${ }^{11}$ See Michael Worboys, Spreading germs: disease theories and medical practice in Britain, 1865-1900, Cambridge University Press, 2000, pp. 189, 224-8; G Feldberg, Disease and class: tuberculosis and the shaping of modern north American society, New Brunswick, NJ, Rutgers University Press, 1995, pp. 55-80.
} 


\section{Bovine Tuberculosis and Tuberculin Testing in Britain}

attempts to eliminate bovine tuberculosis. As the Agricultural Research Council (ARC) explained in 1939, "the steady progress accomplished in many countries towards a gradual diminution in the incidence of tuberculosis has been due in large part to the high efficiency of ... tuberculin". 12

Historical research on tuberculin has focused mainly on its medical uses and troubled application in treatment. ${ }^{13}$ Little has been said about its veterinary role, notwithstanding the important part it came to play in the identification and eradication of bovine tuberculosis in cattle. Work on bovine tuberculosis, itself an underdeveloped field, has also tended to ignore the value ascribed to tuberculin. Instead, attention has concentrated on debates surrounding the construction of the disease as a zoonosis and a threat to public health; the position of bovine tuberculosis in the development of germ theories; and on the role of milk in its transmission. ${ }^{14}$ Interest in attempts to stamp out the disease has highlighted the politics of milk and the controversy surrounding pasteurization. ${ }^{15}$ This article puts forward a different narrative, one in which the emphasis in combating tuberculosis was placed on the identification and slaughter of diseased livestock encouraged by state-supported schemes linked to market incentives. It suggests that tuberculin testing became central to moves to identify tuberculous animals in interwar Britain as part of attempts to stamp out the disease, but that testing remained half-hearted, nevertheless, and encountered opposition. It also examines the development of tuberculin as a diagnostic agent, its role in moves to eradicate bovine tuberculosis between 1890 and the passing of the 1937 Agriculture Act, which established the rudiments of a national system of testing, and it explores why tuberculin came to occupy the position it did. However, despite its relatively early appearance and acceptance as the key to stamping out the disease, tuberculin was not effectively used until after the Second World War because a combination of technical and financial factors frustrated the widespread adoption of testing. These factors were exacerbated by competing and conflicting scientific, bureaucratic, professional and commercial interests. Considerable effort therefore went into the pursuit of a simple and reliable test that would reassure the Ministry of Health, MAF, veterinarians and farmers that tuberculin was reliable. In looking at these issues, the paper points to the tensions between the Medical Research Council (MRC) and the Ministry of Health on the one hand, and MAF on the other. These tensions reflected two different approaches to bovine tuberculosis, one concerned with public health; the other with the farmer.

\footnotetext{
${ }^{12} \mathrm{~J}$ Basil Buxton and R E Glover, Tuberculin tests in cattle, London, HMSO, 1939, p. 7.

${ }^{13}$ Smith, op. cit., note 1 above, pp. 57-62; Bryder, op. cit., note 1 above, pp. 25-6, 35-6, 191-3; Worboys, op. cit., note 11 above, pp. 224-8.

${ }^{14}$ Peter J Atkins, 'White poison? The social consequences of milk consumption, 1850-1930', Soc. Hist. Med., 1992, 5: 207-27; Bryder, op. cit., note 1 above, pp. 133-8, 245-7; Barbara G Rosenkrantz, 'The trouble with bovine tuberculosis', Bull. Hist. Med., 1985, 59: 155-75; Smith, op. cit., note 1 above, pp. 175-94; Keir Waddington, 'The science of cows: tuberculosis, research and the state in the United Kingdom, 1880-1911', Hist. Sci., 2001, 39: 355-81;
}

Worboys, op. cit., note 11 above, pp. 193-233; Deborah Dwork, 'The milk option: an aspect of the history of the infant welfare movement in England, 1898-1908', Med. Hist., 1987, 31: 51-69. On the role of meat, see Keir Waddington, " "Unfit for human consumption": tuberculosis and the problem of infected meat in late Victorian Britain', Bull. Hist. Med., 2003, 77: 636-61.

${ }^{15}$ See Atkins, op. cit., note 10 above, 37-51; L Margaret Barnett, 'The People's League of Health and the campaign against bovine tuberculosis in the 1930s', in Smith and Phillips (eds), op. cit., note 6 above; Bryder, op. cit., note 1 above, pp. 133-8. 


\section{Keir Waddington}

\section{Tuberculin, Diagnosis and Eradication 1890-1914}

Research into the use of tuberculin in identifying tuberculous cattle started shortly after Koch's announcement of its discovery and, from the start, studies of its veterinary use ran in parallel with work on its medical properties. Initially, research concentrated on its therapeutic potential but, as evidence mounted that tuberculin had few curative properties, attention shifted to its diagnostic value. ${ }^{16}$ Interest was motivated by difficulties in detecting infected cattle in the early stages of the disease, and by confusion in prosecutions for the sale of tuberculous meat as to whether the animal from which the meat came was diseased or not. Veterinarians and medical officers of health had traditionally relied on a physical (or naked eye) examination but this had proved untrustworthy. Early symptoms of diarrhoea and low milk yield were mistaken for other diseases, and, as the Encyclopaedia of veterinary medicine (1923) explained, in the early stages "it is difficult or almost impossible to make a positive diagnosis". ${ }^{17}$ Only in advanced cases, when the animal was "a veritable living skeleton", was the disease considered obvious. ${ }^{18}$ Veterinary manuals noted that clinical diagnosis "even by the most expert clinical examiner" was always unreliable'. ${ }^{19}$ Tuberculin appeared to offer the solution, as studies suggested that when a small dose was injected subcutaneously, cows with bovine tuberculosis exhibited a rise in temperature, which could be measured, thus providing a more certain guide than a visual examination. ${ }^{20}$

The discovery of tuberculin's diagnostic properties heartened veterinary and public health campaigners, who called for the eradication of bovine tuberculosis. Eradication, or stamping out, whereby all infected livestock are identified and slaughtered, often with compensation awarded, has formed the mainstay of Western European attempts to prevent and limit epizootic diseases since the early eighteenth century. Part of a choice of strategies, the use and extent of slaughter programmes depends on the nature of the disease and the cost-effectiveness of elimination. Support for stamping out policies was stimulated by the cattle plague of the $1860 \mathrm{~s}$ and eradication programmes were adopted by most European states, notably to deal with rinderpest, pleuro-pneumonia, and foot-andmouth. ${ }^{21}$ Bovine tuberculosis, because it was a chronic rather than an acute condition, difficult to detect, and infected a large number of livestock, was more problematic when it came to eradication than epizootic diseases like rinderpest. However, a similar ideology of stamping out was applied, even if measures to achieve this were at first impractical and encountered staunch resistance. Since the application of tuberculin appeared to offer a reliable method of determining which animals were infected, it removed an important

\footnotetext{
16 'Dr Koch's remedy and tuberculous meat and milk', Sanitary Record, 15 Dec. 1890, pp. 286-7; 'Tuberculosis in animals', ibid. p. 290; Edgar Crookshank, 'The tubercle bacillus', J. R. Agric. Soc. Engl., 1891, 2: 94; 'Experiments with tuberculin on cattle', J. comp. Pathol. Ther., 1891, 4: 173-7.

${ }^{17}$ George Wooldridge (ed.), Encyclopaedia of veterinary medicine, surgery and obstetrics, 2 vols, London, H Frowde and Hodder \& Stoughton, 1923, vol. 1, p. 91.

${ }^{18}$ Edward Courtenay and Frederick Hobday, Manual of the practice of veterinary medicine, London, Baillière, Tindall \& Cox, 1913, p. 449.
}

\footnotetext{
${ }^{19}$ British Congress on Tuberculosis, 1901, 4: 111.

${ }^{20}$ James Law, 'An account of the special investigation of bovine tuberculosis', Public Health, 1895/6, 8: 132; Meredith Young, 'Legislative measures necessary for the abolition of tuberculosis in cattle', Public Health, 1898/9, 11: 613.

${ }^{21}$ See John R Fisher, 'Cattle plagues past and present: the mystery of mad cow disease', J. contemp. Hist., 1998, 33: 215-28; idem, 'To kill or not to kill: the eradication of contagious bovine pleuro-pneumonia in western Europe', Med. Hist., 2003, 47: 314-31; Worboys, op. cit., note 11 above, pp. 43-72.
} 


\section{Bovine Tuberculosis and Tuberculin Testing in Britain}

barrier to stamping out the disease. It was thus quickly incorporated into eradication schemes.

By the mid-1890s, it was accepted in Europe and North America that the "general application" of tuberculin was the best means of tackling bovine tuberculosis in cattle. ${ }^{22}$ A number of strategies were adopted that built on earlier attempts to stamp out epizootics but it was the Danish approach to eradication that became the model for many European states. Denmark had an innovative dairy industry, and a progressive programme to eliminate bovine tuberculosis was devised in the early 1890s by the veterinarian Bernhard Bang, professor of pathology and therapeutics at the Royal Veterinary School, Copenhagen. In the process of studying the diagnostic properties of tuberculin, Bang had become convinced of its effectiveness. ${ }^{23}$ Won over by the idea that bovine tuberculosis was purely a contagious disease, he advocated that every herd should be tested with tuberculin. Those cows that reacted to the test were to be separated from the main herd to prevent further infection. He recommended that only advanced cases be slaughtered, with the rest fattened before they were sold as food. Bang suggested that this should be followed by annual testing and proposed that all reacting animals be replaced with tested stock. Bang's programme found support in the Danish government: in 1893 an Act for the Prevention of Infectious Diseases among Domestic Animals was passed and state funding made available to encourage Danish farmers to stamp out bovine tuberculosis. ${ }^{24}$

Bang's approach to eradication and the Danish policy was copied and applied across Europe with some regional variations. Although Bang's system was slow and costly, it had the benefit of being flexible and adaptable to different levels of herd management. It also allowed farmers to keep valuable stock and did not interfere with breeding. Bang's programme was not the only approach to eradication that utilized tuberculin, however. Competing methods were suggested. Robert Ostertag, the German expert on meat inspection, proposed a modified version that concentrated on breeding disease-free herds. Emil von Behring, winner of the first Nobel Prize in Physiology or Medicine and better known for his work on diphtheria, recommended the inoculation of cattle with tubercle bacilli of human origin that was non-virulent for cows as a way of building up resistance. ${ }^{25}$ Despite the different nature of these approaches, all relied on the application of tuberculin to weed out diseased livestock.

In Britain, similar enthusiasm was expressed for tuberculin. Calls had been made throughout the 1880s and 1890s to include bovine tuberculosis under the 1869 Contagious Diseases (Animals) Act, which had been passed in the wake of the cattle plague of the $1860 \mathrm{~s}$ to stamp out epizootics. ${ }^{26}$ However, difficulties with identifying tuberculous livestock, which had fuelled fears that a large percentage of the national herd would have to be slaughtered, resulting in ruin, had stopped any eradication policy from being pursued.

\footnotetext{
${ }^{22}$ The Times, 22 April 1895, p. 4.

${ }^{23}$ Bernhard Bang, 'Measures taken against animal tuberculosis in Denmark', J. comp. Pathol. Ther., 1908, 21: 288.

${ }^{24}$ 'Establishing a tuberculosis-free dairy herd', J. Ministry Agric., 1924/5, 31: $138-49$.
}

\footnotetext{
25 'Immunisation against tuberculosis by von Behring's method', J. comp. Pathol. Ther., 1906, 19: $86-8$.

${ }^{26}$ For the Contagious Diseases (Animals) Acts, see J R Fisher, 'The economic effects of cattle diseases in Britain and its containment', Agric. Hist., 1980, 54: 278-94.
} 


\section{Keir Waddington}

The emphasis had thus shifted from prevention to the regulation of meat and milk. Tuberculin served to revive the debate on prevention and eradication.

Experiments on tuberculin in Britain in the 1890 s were conducted at the Royal Veterinary College (RVC), first by Edgar Crookshank, professor of bacteriology and comparative pathology at King's College London, and then by John McFadyean, principal of the RVC and editor of the Journal of Comparative Pathology and Therapeutics. Both tentatively confirmed the diagnostic properties of tuberculin. ${ }^{27}$ Within a few years, tuberculin and the approach advocated by Bang were embraced by those groups in the veterinary and medical communities which argued that the only way effectively to check infection from bovine tuberculosis was to stamp out the disease in cattle. With boiling and pasteurization of milk unpopular, and with regular clinical inspections unreliable, tuberculin testing, as the British Medical Journal explained, was quickly seen as the best "hope for a great diminution of bovine tuberculosis in this country". ${ }^{28}$ The meat trade came out in support, seeing in testing a means of placing responsibility on stockowners. ${ }^{29}$ However, the fragmented nature of these interest groups, and the lack of co-ordinated pressure, ensured that support for testing was not always effectively translated into policy. ${ }^{30}$

Tuberculin received official support from the Royal Commission on Tuberculosis of 1896 to 1898 . Appointed to recommend measures to combat bovine tuberculosis after the 1890 to 1895 Royal Commission on the disease had failed to outline any practical policies, and convinced that "it is impossible to detect the presence of limited or localized tuberculosis in living animals from its outward appearance", it endorsed the diagnostic use of tuberculin. The commissioners had asked McFadyean to report on the effectiveness of tuberculin as a diagnostic tool. Keen to use the commercial production of tuberculin to boost the finances of the RVC, McFadyean was optimistic about its use. On the basis of McFadyean's findings, the commissioners confirmed the value of tuberculin as a diagnostic aid. They were also impressed by Bang's approach and argued that the Board of Agriculture should establish a "gratuitous" testing service for stockowners who, it was hoped, would use it to isolate reacting animals. ${ }^{31}$ As part of a wider strategy to limit infection from bovine tuberculosis that included public abattoirs and better meat inspection, the commissioners embraced the notion of "gradual extinction" through a voluntary solution. ${ }^{32}$

The voluntary line of attack favoured by the commissioners was to become part of a general approach to milk regulation in the interwar period. ${ }^{33}$ It was welcomed by the powerful farming lobby, which resisted state intervention in the dairy industry. If a voluntary programme limited the nature of state intervention, it was also less costly than a state sponsored mass testing and eradication programme, and was felt to be less likely to cripple

\footnotetext{
${ }^{27}$ Crookshank, op. cit., note 16 above, p. 94; John McFadyean, 'Experiments with tuberculin in cattle', $J$. R. Agric. Soc. Engl., 1891, 2: 29-35.

${ }^{28} \mathrm{Br}$. med. J., 1897, i: 993.

${ }^{29}$ Harold Scurfield, 'Suggestions with a view to the encouragement of the use of tuberculin', Public Health, 1895/6, 8: 41; Meat Trades' Journal and Cattle Salesman's Gazette, 24 Oct. 1895, p. 510.

${ }^{30}$ See Peter Atkins, 'Lobbying and resistance with regard to policy on bovine tuberculosis: an inside/ outside model of Britain, 1900-1939', given at 'From
}

urban penalty to global emergency: current issues in the history of tuberculosis', Social History of Medicine conference, Sheffield, March 2002.

${ }^{31}$ Royal Commission on Tuberculosis, Report of the Royal Commission appointed to inquire into the administrative proceedings for controlling the danger to man through the use as food of the meat and milk of tuberculous animals, London, HMSO, 1898.

${ }^{32}$ The Times, 4 Nov. 1895, p. 4.

${ }^{33}$ See Phillips and French, op. cit., note 10, pp. 371-88. 


\section{Bovine Tuberculosis and Tuberculin Testing in Britain}

farming, or result in what some feared would be a milk famine if all cattle were tested and the tuberculous slaughtered. ${ }^{34}$ However, even the voluntary approach adopted was criticized as too expensive. To get round this problem, campaigners suggested that responsibility should rest with the agricultural industry and the market, arguing that the creation of a system of market premiums for meat and milk guaranteed free from the disease would encourage farmers to test their herds and buy tested cattle. ${ }^{35}$ Measures adopted by the state in the interwar period came to combine the two approaches, ensuring that moves to tackle bovine tuberculosis mixed voluntary provision with market incentives.

The Danish eradication programme and the recommendations of the Royal Commission were crucial in shaping local sanitary authority initiatives to tackle bovine tuberculosis. Glasgow was one of the first local authorities to act, building on earlier efforts to improve the quality of meat in the city. In 1899, the Health Committee issued instructions that stressed the importance of regular tuberculin testing. ${ }^{36}$ Birmingham followed in 1908 after a fact finding mission to Denmark. A system of testing was established to encourage the eradication of bovine tuberculosis "from a certain number of dairy herds supplying milk". Under the scheme, free twice-yearly tests were offered to all dairymen within ten miles of the city and "a list ... supplied to any person in the town, of those farms which are free from the disease". ${ }^{37}$ Although some local authorities launched similar programmes that emphasized the value of testing, most remained reluctant to act, either because they were "unable to screw up the courage, or perhaps [unwilling] to unbutton their pockets". 38

Despite well-publicized efforts by some local authorities to promote the eradication of bovine tuberculosis, and pressure from the medical press and anti-tuberculosis organizations, neither the Board of Agriculture nor the Local Government Board (LGB) was prepared to implement a mass testing programme. Both believed that "there is no reasonable probability that the disease [bovine tuberculosis] will ever be extirpated". ${ }^{39}$ Although the Board of Agriculture had reluctantly agreed to offer free tuberculin to stockowners some months after the Royal Commission reported, it was wedded to administrative controls and was sceptical of experimental research. ${ }^{40}$ Throughout its evidence to the Royal Commission, the Board had tried to duck responsibility, claiming that bovine tuberculosis was a public health issue that should be dealt with by the LGB. ${ }^{41}$ It was unwilling to act, hampered as it was by the strong farming lobby and concerns about business interests, despite its enthusiastic support of eradication for epizootics. The Board recognized that compulsion was undesirable, commenting that it was hopeless to implement the recommendations of the Commission "in the face of disapproval from the Associated Chambers of Agriculture", which had been established to lobby government on the control of epizootics following the

\footnotetext{
${ }^{34}$ John Penberthy, 'The veterinary aspects of the tuberculosis problem', J. comp. Pathol. Ther., 1907, 20: 287.

${ }^{35}$ Editorial, 'The stamping out of tuberculosis', J. comp. Pathol. Ther., 1899, 12: 57; Scurfield, op. cit., note 29 above, p. 43.

36 'Prevention of tuberculosis in cattle', Vet. Rec., 7 Oct. 1899, p. 207; Br. med. J., 1899, i: 677.

37 'Prevention of tuberculosis among cattle', Med. Officer, 17 April 1909, p. 824; Brennan de Vine, 'Eradication of tuberculosis from dairy herds supplying
}

milk to Birmingham', J. Meat Milk Hyg., 1911, 1: 138-41; Br. med. J., 1925, i: 309.

38 'Tuberculosis in London', Vet. Rec., 25 Feb. 1893 , p. 470 .

${ }^{39}$ Royal Commission on Tuberculosis, op. cit., note 31 above, p. 2; Annual report of the Veterinary Department for the year 1890, London, 1891, p. 7.

${ }^{40}$ The Times, 3 Jan. 1899, p. 13; Worboys, op. cit., note 11 above, pp. 58, 223-4.

${ }^{41}$ Royal Commission on Tuberculosis, op. cit., note 31 above, pp. 13-14. 


\section{Keir Waddington}

cattle plague of the $1860 \mathrm{~s} .{ }^{42}$ The Board argued that plans to stamp out bovine tuberculosis were more problematic and expensive than schemes to eradicate rinderpest or pleuropneumonia, dismissing the methods employed by Bang as difficult and liable to place too heavy a burden on farmers. Evidence that approximately a quarter of the national herd was infected with bovine tuberculosis saw the Board baulk at the financial implications of a mass testing programme, which it estimated would cost $£ 635,000$ and $£ 4 \mathrm{~m}$ in compensation if all reacting animals were slaughtered. It believed that the public could not be expected to pay this amount and that the loss to agriculture would be considerable. ${ }^{43}$

The Board put forward other technical reasons as to why attempts to stamp out bovine tuberculosis would be difficult. It was worried that the disease was hard to detect, as it was unconvinced by the value of tuberculin. Studies on tuberculin by George Thomas Brown, chief veterinary advisor to the Board, questioned its reliability. Trained as a veterinary surgeon, Brown had assisted J B Simonds at the Privy Council in devising administrative mechanisms to stamp out rinderpest, succeeding Simonds as chief veterinary officer in 1872. Although other studies upheld the usefulness of tuberculin, Brown was strongly influenced by observational and anecdotal evidence that suggested that tuberculin could not always be relied upon to give an accurate diagnosis. ${ }^{44}$ After undertaking a study for the Board, Brown reported that tuberculin failed to identify one in ten diseased cattle. For Brown, this was sufficient grounds to question the dependability of the test. ${ }^{45}$ Conflicting scientific views about tuberculin appeared to support his stance and provided the Board with loopholes.

The LGB was equally reluctant and was accused of sheltering behind the Royal Commission so that it could avoid action. ${ }^{46}$ It is clear that John Burns, as the minister responsible, took little interest in food, and the LGB was beset with internal problems. ${ }^{47}$ Only under pressure from public health doctors and veterinary surgeons keen to assert their public health credentials were the LGB and Board of Agriculture manoeuvred into a position where they had to do something. However, concerns about the reliability of tuberculin saw measures to stamp out bovine tuberculosis recommended by the Board of Agriculture and the LGB initially stressing the authority of visual inspection and a cautious approach. Looking back, Walter Fletcher, the first secretary of the MRC, was convinced that had they acted more effectively, many of the "practical problems ... of advising and encouraging farmers to keep tubercle-free herds" would not have been encountered in the 1920s. ${ }^{48}$

Veterinarians and farmers began to echo the scepticism about tuberculin expressed by the Board of Agriculture. After an initial wave of panic following the report of the Royal Commission of 1896 to 1898, farmers became more cautious about tuberculin. The incidence of voluntary testing fell once public concern had subsided, despite encouragement

\footnotetext{
${ }^{42}$ The Times, 15 Aug. 1898, p. 12; A H Matthews, Fifty years of agricultural politics: a history of the Central Chamber of Agriculture 1865-1915, London, P S King, 1915.

${ }^{43}$ The Times, 15 Aug. 1898, p. 11.

${ }^{44}$ National Veterinary Association, Sixteenth general meeting, London, 1898, pp. 13-29; J McLaughlan Young, 'Tuberculin testing', Vet. Rec., 20 June 1896, pp. 681-3.
}

\footnotetext{
45 'The degree of prevalence of bovine tuberculosis', Public Health, 1893/4, 6: 30

${ }^{46}$ Meat Trades' Journal and Cattle Salesman's Gazette, 17 Feb. 1898, p. 874.

${ }^{47}$ Jim Phillips and Michael French, 'Adulteration and food law, 1899-1939', Twentieth Century $\mathrm{Br}$. Hist., 1998, 9: 357-8.

${ }^{48}$ PRO: W Fletcher to Eastwood, 29 April 1922, FD 1/154.
} 


\section{Bovine Tuberculosis and Tuberculin Testing in Britain}

from local authorities. Notions that the disease was hereditary persisted among farmers, encouraging fatalism. In addition, testing was seen as a "bug-bear" that disrupted normal farm routines. ${ }^{49}$ Early methods of testing through subcutaneous injections required rigorous procedures that were seldom possible on most farms. Ideally, temperatures had to be monitored over a fifteen- to eighteen-hour period and the test was not the "child's play" that supporters claimed. ${ }^{50}$ Veterinarians started to complain of problems with the subcutaneous method of testing, which produced errors "with much greater frequency than many suppose". ${ }^{51}$ Tuberculin did not have to conform to any standards and this meant that its chemical composition and strength varied, ensuring a marked margin for error. In addition, the subcutaneous test was not very sensitive: it failed to produce a reaction in cattle in the early stages of the disease and was unreliable in animals already exhibiting a raised temperature, such as before calving. The exact nature of the temperature change, often only a few degrees, was also difficult to spot, especially for inexperienced veterinarians. These factors produced "numerous uncertain reactions" that cast doubt on the trustworthiness of tuberculin. ${ }^{52}$

Anxiety about the effectiveness of tuberculin was intensified by evidence that "unscrupulous cattle owners" were abusing the test. At first it was felt that sequential doses might have a beneficial effect, helping to immunize herds, but by the mid-1890s it was clear that this was not the case and that the practice masked signs of the disease. "In order to defeat the test", some farmers would therefore inject one or more doses of tuberculin into their livestock the day before the herd was due to be tested to ensure no reaction was produced. ${ }^{53}$ It helped that those local sanitary authorities that favoured testing often gave advance warning, allowing abuses to flourish. After investigation in 1899, the north-western branch of the Society of Medical Officers of Health believed that dairy farmers in the region had been advised "to inoculate their stock with tuberculin . . f for the purpose of making abortive any subsequent test". ${ }^{54}$ Concerns about doping increased doubts about the reliability of tuberculin.

To get round these problems, other modes of testing were suggested, often adapting tests devised for humans. These included administering drops of tuberculin to the conjunctival sac or painting tuberculin onto abraded skin. ${ }^{55}$ Methods were also combined in the hope of producing better results. ${ }^{56}$ Although many of these new procedures were not as effective as subcutaneous injection, the intradermal method whereby tuberculin was injected into the dermis did result in fewer "uncertain reactions". A skin test for humans had been introduced in 1907 and was quickly adapted for cattle. It was argued that the reactionmanifested as a swelling at the site of the injection-was not only more reliable but also could be read with greater accuracy. ${ }^{57}$ The results were not complicated by age, temperature, or recent calving.

\footnotetext{
${ }^{49}$ Scurfield, op. cit., note 29 above, p. 239.

50 'Tuberculosis in cattle', Vet. Rec., 6 April 1895, p. 557.

${ }^{51}$ Walter Jowett, 'Some observations on the tuberculin test', J. comp. Pathol. Ther., 1914, 27: 136.

${ }^{52}$ Arthur Littlejohn, 'Tuberculin as a diagnostic agent', Vet. J., June 1911, pp. 332-4.

${ }^{53}$ Walter Jowett, 'Tuberculin as a diagnostic agent', J. comp. Pathol. Ther., 1909, 22: 11.
}

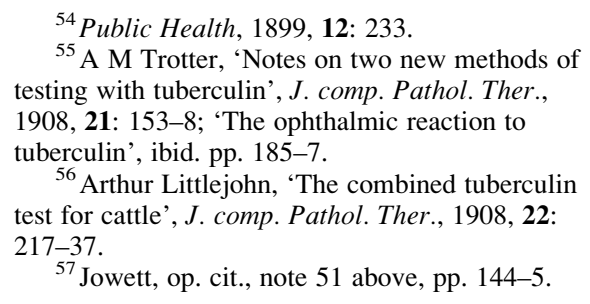

${ }^{54}$ Public Health, 1899, 12: 233.

${ }^{55}$ A M Trotter, 'Notes on two new methods of testing with tuberculin', J. comp. Pathol. Ther., 1908, 21: 153-8; 'The ophthalmic reaction to tuberculin', ibid. pp. 185-7.

${ }^{56}$ Arthur Littlejohn, 'The combined tuberculin test for cattle', J. comp. Pathol. Ther., 1908, 22: 217-37.

${ }^{57}$ Jowett, op. cit., note 51 above, pp. 144-5. 


\section{Keir Waddington}

\section{Tuberculin Contested 1920-1930}

Despite differences in the mode of application, and concerns about reliability, by the outbreak of war in 1914 the diagnostic value of tuberculin had been accepted. Although some veterinarians grumbled that methods of testing were complicated and took up time "the busy country practitioner could not afford", many came to see it as a "professional lifeline". ${ }^{58}$ If the surveying records do not support a quantitative survey to show the extent to which testing was employed by veterinarians, qualitative evidence does suggest that in the interwar years tuberculin testing became an important source of income for a profession facing financial stringency with the declining significance of the horse, the traditional mainstay of veterinary practice. By the mid-1920s, the use of tuberculin by veterinary surgeons had become widespread "in order to arrive at a diagnosis" as veterinarians adapted testing procedures to suit the realities of most farms. ${ }^{59}$ They thus defended the value of tuberculin as the best means of controlling bovine tuberculosis. As Major Douglas of the National Veterinary Association told MAF, "clinical examination, no matter how frequently it was done, was never going really to eradicate the disease. We felt that the reliability of the tuberculin test was what we had to depend upon". ${ }^{60}$

As interest grew in the production of disease-free milk and the eradication of bovine tuberculosis in the aftermath of the war, further studies were undertaken in France, the United States and Denmark on the various tuberculin tests to determine their relative effectiveness. In the process, earlier doubts about the reliability and sensitivity of tuberculin were reinforced. Investigations in Britain were shaped by similar interests. Where, however, bovine tuberculosis had come to be seen as primarily an economic problem affecting agriculture in continental Europe and North America, in Britain it continued to be constructed within a public health framework. The definition of bovine tuberculosis as essentially a public health concern meant that the lead in tuberculin research was taken by the MRC, which had been set up following the 1911 National Insurance Act to promote research into tuberculosis. ${ }^{61}$

The MRC established the Tuberculin Committee in 1921 to investigate the diagnostic and therapeutic uses of tuberculin and the reliability of the test. The veterinary use of tuberculin was included, "in view of the connected problems of the hygiene of milk and of bovine tuberculosis in man", after pressure was applied for stockowners keen to encourage the development of a more effective test. The Ministry of Health was also eager to sponsor a reliable test to help promote a safe milk supply. Renewed anxiety about diseased milk and public health saw concern directed at the dairy industry, as part of attempts to promote consumer confidence in the purity of the milk supply. ${ }^{62}$

The initial supremacy of the MRC was hardly surprising. Under Fletcher, the MRC came to dominate biomedical research in the interwar period. Convinced that "tuberculosis of cattle is a matter of great moment in public health owing to the bovine source of much

\footnotetext{
${ }^{58} \mathrm{~J}$ Watson, 'More about tuberculin', Vet. Rec., 31 Dec. 1898 , p. 388 .

${ }^{59}$ PRO: MAF diseases of animals branch circular letter, MAF 35/1103.

${ }^{60}$ PRO: 'Eradication of bovine tuberculosis', 6 Aug. 1930, MAF 35/659.
}

\footnotetext{
${ }^{61}$ See Linda Bryder, 'Tuberculosis and the MRC', in Joan Austoker and Linda Bryder (eds), Historical perspectives of the role of the MRC, Oxford University Press, 1989, pp. 1-21.

${ }^{62}$ PRO: Tuberculin committee minutes, 9 June 1923, FD 1/154.
} 


\section{Bovine Tuberculosis and Tuberculin Testing in Britain}

tuberculosis infection among human beings", Fletcher argued that the veterinary use of tuberculin was of "obvious importance". ${ }^{63}$ He wanted the MRC to take responsibility for tuberculin research, believing that the Board of Agriculture and its successor, MAF, had failed to carry out the necessary work under Stewart Stockman, its chief veterinary officer and director of veterinary research. Although Stockman had encouraged veterinary research in the Edwardian period, and had worked with McFadyean on tuberculin, he did not consider further investigation into the test necessary. ${ }^{64}$ At MAF he maintained the Board of Agriculture's cautious approach to supporting any experimentation that might threaten existing administrative controls and Fletcher saw him as "a notorious backwoodsman". ${ }^{55}$ Stockman's conservatism frustrated agricultural researchers and encouraged Fletcher to push the MRC into offering farmers that "scientific help, or even effective sympathy" he believed MAF had failed to provide. ${ }^{66}$ Although Fletcher's interests lay elsewhere, research into tuberculin offered him an opportunity to extend the MRC's control of veterinary as well as medical investigation, a policy he relentlessly pursued throughout his time at the Council. ${ }^{67}$ Research into tuberculin thus became caught up in inter-departmental conflicts. Problems at MAF over funding, the lack of suitable staff, and the poor position of veterinary research initially allowed the MRC to dominate the research programme.

From the start, the Tuberculin Committee was aware of the utility of tuberculin in testing cattle, and that technical problems and evidence of doping was discouraging its use. Members of the Committee were also worried that, not only were infected animals being passed as safe, so introducing the disease into the food chain, but also that valuable livestock were unnecessarily condemned when false results were obtained. This combination of public health and farming interests served to dominate tuberculin research in the interwar period. With subcutaneous injections producing "anomalous results", and under pressure from the Ministry of Health, the Committee looked for answers. It was conscious that "until the day when some method of successfully immunizing cattle against tuberculosis is discovered" tuberculin testing was the best defence against the disease. An investigation was therefore launched in 1921 to determine why discrepancies arose, and to come up with "a trusty and simple" test. ${ }^{68}$

Much of the research for the Committee was undertaken by the Institute of Animal Pathology at Cambridge. For the MRC, the Institute was ideal. Under the control of James Basil Buxton, the newly appointed professor of animal pathology, it had developed from the Cambridge School of Agriculture, becoming a separate institute in 1923. Buxton had begun his career lecturing on veterinary hygiene at the Royal (Dick) Veterinary College in Edinburgh, before moving to the Wellcome Physiological Research Laboratories in 1912. In 1922, he was appointed to direct the MRC's farm laboratory at Cambridge. If Buxton had already worked for the MRC, the Cambridge Institute had other advantages. It was one of the few veterinary research institutes in the country, and was moreover well organized and

${ }^{63}$ PRO: W Fletcher to Treasury, 23 July 1923, T $161 / 213$.

${ }^{64} \mathrm{~J}$ McFadyean, 'Experiments with tuberculin on cattle', J. comp. Pathol. Bacteriol., 1991, 4: 29.

${ }^{65}$ PRO: Memorandum, 30 July 1923, T 161/213.

${ }^{66}$ PRO: W Fletcher to Eastwood, 29 April 1922, FD

\footnotetext{
${ }^{67}$ See Joan Austoker, 'Walter Morley Fletcher and the origins of a basic biomedical research policy', in Austoker and Bryder (eds), op. cit., note 61 above, pp. 23-33.

${ }^{68}$ PRO: W Fletcher to Holland-Hibbert, 30 July 1925, FD 1/155.
} $1 / 154$. 


\section{Keir Waddington}

better funded than the National Institute for Research in Dairying, Reading. ${ }^{69}$ However it remained squeezed by financial constraints, and by a sense that the MRC should concentrate on areas of direct benefit to clinical medicine, which ensured that much of the research by Buxton and the Institute's staff was conducted on a shoestring, with the aid of farmers. $^{70}$

When the report was published in 1925, the Committee confirmed that while the subcutaneous test was satisfactory under laboratory conditions, it was unreliable under "normal farm conditions" reflecting the criticisms made by veterinarians and farmers. To overcome this problem it put forward the double intradermal method whereby concentrated tuberculin was injected into the deep layers of a shaved portion of the neck. In some cases a marked swelling, which was hot and tender to the touch, was seen after forty-eight hours. This was a positive reaction. In others, the swelling was pea-sized and a second injection was administered. This was felt to provide a diagnostic dose, as in infected cattle the little swelling became large and easy to detect. In a farm environment there were clear advantages. Cattle did not have to be "rested" before or during the test to stabilize their temperature, nor did the intradermal method require careful temperature recordings and it was harder to falsify the results. ${ }^{71}$

The MRC's support for tuberculin was reflected in legislative attempts to prevent the transmission of bovine tuberculosis through milk. Provision had been curtailed because of a series of government retrenchments under the Geddes axe, and by political infighting between the Ministry of Health and MAF. With neither government departments nor doctors able to make up their minds over what to do about milk, and with the Ministry of Health and MAF worried about business reactions, general milk policy at first remained uncertain. However, under the 1923 Milk (Special Designation) Order the voluntary principle of testing and market incentives was firmly embodied. The Order graded milk: tuberculin tested milk was labelled Grade A (TT). It differed from other milk in Grade A, which was regulated by the Ministry of Health, by its reliance on tuberculin and the different bacteriological threshold adopted. For milk to qualify it had to come from herds tested twice yearly. All reacting cattle were removed, and all additions to the herd had to pass a tuberculin test. Testing was extended by the 1925 Tuberculosis Order and the 1926 Milk and Dairies Order, with compensation paid for cattle with tuberculosis of the udder, tuberculous emaciation, and chronic coughs. ${ }^{72}$ Despite criticism of the Orders and their limited nature, MAF felt that they were a step towards removing "the source of immediate danger to human health" by eliminating the "most" diseased livestock. ${ }^{73}$ In the following year, local authorities were required to inspect and test cattle suspected of bovine tuberculosis following reports from slaughterhouses of high levels of the disease. Many appointed whole-time veterinary officers to conduct the work. ${ }^{74}$ However, imperfect and irregular

\footnotetext{
${ }^{69}$ Keith Vernon, 'Science for the farmer? Agricultural research in England 1909-36', Twentieth Century Br. Hist., 1997, 8: 310-33.

${ }^{70}$ PRO: W Fletcher to Treasury, 23 July 1923, $\mathrm{T} 161 / 213$.

${ }^{71}$ MRC, Tuberculin tests in cattle, with special reference to the intradermal test, London, HMSO, 1925, pp. 77-83, 116.
}

\footnotetext{
${ }^{72}$ See Atkins, op. cit., note 10 above, pp. 37-51; Phillips and French, op. cit., note 10 above, pp. 371-88, for a discussion of milk regulation.

${ }^{73}$ Public Health, 1933, 46: 366; Annual report of the Board of Agriculture, London, 1926.

${ }^{74}$ Vernon, op. cit., note 69 above, pp. 329-31; Atkins, op. cit., note 10 above, pp. 42-4.
} 


\section{Bovine Tuberculosis and Tuberculin Testing in Britain}

inspection, loopholes in the Orders, and their voluntary nature, allowed farmers to avoid testing. ${ }^{75}$

The renewed efforts to extend testing by local authorities and the Ministry of Health, saw veterinary surgeons and stockowners welcome the MRC's report on the double intradermal method, which was considered "simpler and more satisfactory". ${ }^{76}$ For J Jones, a veterinary surgeon in Gloucester, "the intradermal test is a godsend". Veterinarians came to regard this method as simple, convenient and quick. It had the additional appeal of not interfering with farm practices or with milk yields. ${ }^{77}$ Nor did the method require early morning or night testing like subcutaneous injection, and involved fewer visits (often only three), an important factor for "a busy singlehanded practitioner". As W T D Broad, a veterinary surgeon in Marlborough commented, "it can be done about milking time without disturbing cattle, or interfering with other farming operations; it does not require cattle to be kept in for taking temperatures ... it is also less arduous for the operator and assistants". ${ }^{78}$

However, despite the favourable reception of the MRC's report and the growing use of the double intradermal test by veterinary surgeons, criticism of the method quickly emerged. It was not as simple as the MRC claimed, proving problematic for inexperienced veterinarians because the skittish nature of nervous or sensitive cattle made administering the right dose difficult. ${ }^{79}$ One veterinary surgeon pointed to the "great experience ... required and more manipulative skill" to avoid injecting the subcutaneous tissue, and for interpreting doubtful or borderline reactions, especially in "badly lighted byres". The subjective element of the double intradermal method was attacked; even experienced veterinarians were not entirely happy to make judgements on the size and character of the swelling. ${ }^{80}$ MAF also voiced caution and criticized the method for the latitude that existed in interpreting results. ${ }^{81}$

In response to these criticisms, the Tuberculin Committee admitted that the double intradermal test did have some weaknesses, although it remained convinced that it was the best available. Further investigations were therefore commissioned to reassure the veterinary and farming community, with Buxton and the Institute of Animal Pathology once more playing a leading role. While it was acknowledged that anomalous reactions did occur, these were largely blamed on poor veterinary practices in a climate in which "great carelessness was shown in the way the animals were treated before the injection". 82 Better procedures for interpreting the results were outlined, with the Committee adamant that the double intradermal test gave "the most consistent results regarding the presence or absence of [tuberculosis]". 83

These views were subsequently confirmed by a series of field studies supported by MRC grants. Leslie Jordan, a veterinary pathologist at the Hannah Dairy Research Institute in

\footnotetext{
${ }^{75}$ PRO: Memorandum, 1 March 1937, MAF52/130.

${ }^{76} \mathrm{~J}$ Basil Buxton and Arthur S MacNalty, The intradermal tuberculin test in cattle, London, HMSO, 1928, pp. 32, 3.

${ }^{77}$ PRO: Tuberculin subcommittee minutes, 1 Nov. 1934, MAF 35/338.

${ }^{78}$ Buxton and MacNalty, op. cit., note 76 above, pp. $10-11,14$.

${ }^{79}$ R N Dixey, Tuberculin-tested milk: a study of reorganization for its production, Oxford, Agricultural Economics Research Institute, 1937, p. 98.
}

\footnotetext{
${ }^{80}$ Buxton and MacNalty, op. cit., note 76 above, pp. 17-19; Hyslop Thomson, op. cit., note 3 above, p. 118.

${ }^{81}$ PRO: Note by the tuberculin committee, June 1925, FD 1/156.

${ }^{82}$ Buxton and MacNalty, op. cit., note 76 above; $\mathrm{C}$ Adeane and J Gaskell, 'A segregation method for eliminating tuberculosis from cattle', J. Hyg., 1927/8, 27: 250

${ }^{83}$ Buxton and Glover, op. cit., note 12 above, p. 4.
} 


\section{Keir Waddington}

Ayrshire, conducted a trial eradication scheme between 1929 and 1932. Jordan, who had worked with Buxton at Cambridge, was confident about the utility of tuberculin in producing an accurate diagnosis. Combining field investigations with a scientific study, he demonstrated that a marked reduction in infection was possible through regular testing. In the process, he confirmed the reliability of the double intradermal test, which was consequently recommended by the Hannah as being of "outstanding merit". 84

\section{Agriculture Research and Tuberculin, 1930-39}

Although support for pasteurization grew as a means of safeguarding the public from bovine tuberculosis in the face of "strengthening medical evidence of the hazards of raw milk", and doubts about the reliability of tuberculin persisted, testing became central to efforts to limit the disease in cattle in the mid-1930s. However, as public health measures to prevent infection came under attack as cumbersome and damaging, in spite of renewed concerns about physical deterioration, the emphasis had started to shift to the benefits to farming. ${ }^{85}$ Pressure was growing from bodies such as the National Veterinary Medical Association, Society of Medical Officers of Health, Associated Chambers of Agriculture, and the People's League of Health to transfer responsibility for the eradication of bovine tuberculosis from public health authorities to agricultural and veterinary bodies. By the early 1930s, these groups found an increasingly sympathetic audience in MAF. A transfer to milk production had saved many farmers from financial ruin in the 1920s and early 1930s and MAF wanted to shore up the dairy industry, which had become "the cornerstone of our agriculture". ${ }^{86}$ This concern about the dairy industry saw a change in policy at MAF as it grew apprehensive about the cost of bovine tuberculosis to farming and worried about the possible collapse of the milk market. Studies in the 1920s by the Agricultural Economics Research Institute at Oxford had pointed to the economic problems caused by bovine tuberculosis in terms of milk yield and returns on carcases, and to the savings that could be made if the disease was eradicated.$^{87}$ MAF came to accept that moves to protect the dairy industry "must depend upon the use of tuberculin in determining the freedom or otherwise of the herd from tuberculous infection". ${ }^{88}$ MAF's interest reflected growing concern in the national government about agriculture. It wanted to boost agricultural production, restoring agricultural prices through subsidies during the depression. Given the dairy industry's important role in agriculture, it became a priority. ${ }^{89}$ This desire to protect dairy farming meshed with the ongoing enthusiasm at the Ministry of Health to promote a pure milk supply.

The growing enthusiasm for tuberculin testing at MAF was reflected in a shift in emphasis in tuberculin research. The formation of the Agricultural Research Council (ARC) in 1931 to

\footnotetext{
${ }^{84}$ Jordan, op. cit., note 5 above, p. 3; Alexander Fowler and Norman Wright, Reactors in tuberculin tested (licensed herds), Ayr, Hannah Dairy Research Institute, 1931.

${ }^{85}$ Phillips and French, op. cit., note 10 above, p. 382 .

${ }^{86}$ Cited in David Taylor, 'The English dairy industry, 1860-1930: the need for reassessment', Agric. Hist. Rev., 1974, 22: 153.
}

\footnotetext{
${ }^{87} \mathrm{~V}$ Liversage, Economics of production of grade 'A' (tuberculin tested) milk, Oxford, Clarendon press, 1926.

${ }^{88}$ PRO: Joint Tuberculosis Committee minutes, 8 Oct. 1934, FD 1/4497.

${ }^{89} \mathrm{C}$ Hallas, 'Supply responsiveness in dairy farming', Agric. Hist. Rev., 1991, 39: 14-15.
} 


\section{Bovine Tuberculosis and Tuberculin Testing in Britain}

co-ordinate agricultural research under the Privy Council saw the rationale behind research on veterinary tuberculin alter to match the growing importance of agricultural interests in the eradication of bovine tuberculosis. ${ }^{90}$ Interest in agricultural research had grown in the 1920 s as fears about livestock disease and milk quality intensified with the increasing importance of the dairy industry to agriculture. The ARC was an expression of this. Committed to research that would benefit farming, it saw the combating of animal disease as a priority and joined with the MRC to establish the Joint Tuberculosis Committee in 1933.

Despite growing support for tuberculin in the Ministry of Agriculture and Fisheries, tensions between MAF and the Ministry of Health over the best way to limit infection from tuberculous cattle initially frustrated action. The Ministry of Health had come out in support of pasteurization, which was rejected by MAF in favour of voluntary measures and market incentives linked to testing. ${ }^{91}$ An attempt was made to break the policy deadlock through the appointment in 1932 of the Economic Advisory Council on Cattle Diseases, following reports from local authorities revealing higher levels of bovine tuberculosis than anticipated. The move from public health to farming interests now saw the Ministry of Health sidelined and veterinary ideas about eradication accepted. The Council therefore supported voluntary eradication, returning to ideas expressed in 1917 by the Committee on the Production and Distribution of Milk and being discussed in MAF. ${ }^{92}$ It reiterated the need for the provision of free advice and free tuberculin for those farmers who agreed to make bona fide efforts to clear their herds of tuberculosis. The Council also called for a list of tuberculosis-free herds tested with tuberculin, for loans to help farmers pay for veterinary inspection, and for higher premiums for TT milk. ${ }^{93}$ The recommendations, which reflected a consensus on how bovine tuberculosis should be tackled in agriculture, were evidently designed to protect the farmer not the public.

The growing support for tuberculin in MAF and the recommendations of the Economic Advisory Council were not enough to overcome misgivings about the reliability of tuberculin. The ministry remained anxious, disturbed by studies that continued to point to anomalous results. It therefore approached the Joint Tuberculosis Committee for answers. Although the Committee expressed its confidence in tuberculin, it was mindful that "experience has shown that when attempts are made to eradicate tuberculosis by the application of systematic tuberculin tests, difficulties may, and in fact do, arise". ${ }^{94}$ Concerned that the "official test" sought by the Ministry of Health and MAF in the light of the report of the Economic Advisory Council should be reliable, and keen to promote disease-free herds, the Committee set up a subcommittee to investigate the methods and materials that should be used. The subcommittee was to advise MAF and at the same time meet the expected demand for information from farmers increasingly interested in testing. ${ }^{95}$

The need for research was strengthened by moves to implement the report of the Economic Advisory Council. This was facilitated by on-going debates about milk and bovine

\footnotetext{
${ }^{90}$ For the ARC, see Timothy DeJager, 'Pure science and practical interests: the origins of the Agricultural Research Council, 1930-37', Minerva, 1993, 31: 129-50.

${ }^{91}$ See Atkins, op. cit., note 10 above, pp. 37-51.

${ }^{92}$ Editorial, 'A pure milk supply', Tubercle, 1919/20, 1: 377-8.
}

\footnotetext{
${ }^{93}$ Economic Advisory Council on Cattle Diseases, Report of the Committee on Cattle Diseases, London, HMSO, 1934.

${ }^{94}$ Buxton and Glover, op. cit., note 12 above, p. 1.

${ }^{95}$ PRO: Joint Tuberculosis Committee minutes, 8 Oct. 1934, FD 1/4497; PRO: Kay to Havelock, 26 June 1934, FD 1/4498.
} 


\section{Keir Waddington}

tuberculosis, especially as plans in 1934 by the Milk Marketing Board to distribute cheap and, it was feared, possibly infected milk to schools to stimulate milk consumption provoked immediate concern. ${ }^{96}$ Both MAF and the Ministry of Health remained committed to voluntary measures supported by financial incentives that placed the emphasis on individual farmers, aware that the financial implications of compulsory eradication were too great. Under the 1936 Milk (Special Designation) Order, existing classifications were simplified. "Certified" and "Grade 'A' (TT)" milk were given in the same "accredited" grade, with greater insistence placed on the segregation of tuberculous stock and retesting. The year before, MAF had introduced the tuberculosis (attested herd) scheme, which followed the recommendations of the Economic Advisory Council and paralleled Jordan's work in Ayrshire. Regular examinations were central to the scheme, as on testing "alone depends the fate of individual animals in the herd". ${ }^{97}$ Owners could apply to MAF for an official tuberculin double intradermal test provided no reactors had been found in their herd "on the occasion of the last two tests made on the owner's behalf". If the herd was deemed disease free, it was awarded a "certification of attestation", with a bonus paid for milk sold to the Milk Marketing Board from the herd. Testing was then conducted at six-monthly intervals by MAF inspectors: all reacting cattle had to be segregated to ensure that the licence was maintained. ${ }^{98}$ This method was further formalized in 1937 under a new Agriculture Act, giving further assistance to farmers to improve agriculture. The Act, in creating a veterinarian public health programme, transferred testing duties to a part-time staff at MAF under a two-tier system. Those appointed under Panel B were responsible for tuberculin testing and "eradication duties". The Act also revised the "attested herd" scheme to include all cattle (beef and rearing). To encourage owners to apply for certificates, MAF agreed to make financial assistance available for testing in cases where the number of reactors in a herd was below 10 per cent. These herds came under a new provisional category of "supervised" as an intermediary stage before attested status was acquired. ${ }^{99}$ Tuberculin had thus become "the sheet-anchor of all schemes for the eradication of tuberculosis". 100

With tuberculin now playing such an important role in state sponsored moves to stamp out bovine tuberculosis, studies for the Joint Tuberculosis Committee focused on two main areas: the refinement of testing procedures and the pursuit of pure tuberculin, issues that had been raised in the 1920s. This continuity was hardly surprising: MAF and the Joint Tuberculosis Subcommittee were anxious to explain "discordant results" and to "reassure herd owners and veterinary practitioners, whose confidence in the double intradermal test had been somewhat shaken" following studies that suggested it was not always dependable. ${ }^{101}$ MAF also now had a vested interested in promoting a reliable test to encourage farmers to join its attested herd schemes. Working through the Joint Subcommittee, Buxton and his colleagues continued to argue that the double intradermal method did produce reliable results. They argued that errors were either caused by veterinarians' unfamiliarity with the test or the lack of standardization. ${ }^{102}$

\footnotetext{
${ }^{96}$ PRO: Milk in schools scheme, 1934, ED 50/81.

${ }^{97}$ Br. med. J., 1939, ii: 1235.

${ }^{98}$ J. Ministry Agric., 1934-35, 41: 1041-2.

99 'Employment of part-time officers in the state veterinary service', Vet. Rec., 1938, 50: 239; J. Ministry Agric., 1937-38, 44: 205-6.
}

\footnotetext{
${ }^{100} \mathrm{Br}$. med. J., 1939, i: 1149.

${ }^{101}$ PRO: Joint Tuberculosis Committee minutes, 13 Feb. 1934, FD 1/4498.

${ }^{102}$ Buxton and Glover, op. cit., note 12 above, p. 1.
} 


\section{Bovine Tuberculosis and Tuberculin Testing in Britain}

Studies by the Bureau of Animal Industry in the United States in the 1920s had revealed that the medium used for producing tuberculin could introduce non-specific substances that falsified results. In response, the Bureau sought to produce tuberculin that was free from "contamination". ${ }^{103}$ This research was repeated by Buxton and his colleagues at Cambridge as pressure grew from MAF for a reliable test. Fear was aroused by studies that showed that many brands of tuberculin available in Britain were of a low potency, often inert or virtually useless. With attention focusing on the value of tuberculin in eradicating bovine tuberculosis, standardized tuberculin was considered vital to prevent "well planned and necessarily expensive scheme[s]" from being "wrecked". 104

Buxton and his staff initially concentrated on eliminating the unwanted components that produced swelling. Further studies looked at the properties of synthetic medium, with researchers at Cambridge working closely with the Bureau of Animal Industry. Although the MRC had pressed for tuberculin to be included under the 1925 Therapeutic Substances Act, it was not until 1935, following an extension of testing under MAF, and reflecting fears that contaminated tuberculin might spread foot-and-mouth disease, that legal controls were introduced to prevent inferior products being used or produced. ${ }^{105}$ However, the achievement of standardized tuberculin free from impurities proved elusive. Both the Institute and the Wellcome Physiological Research Laboratories continued to point to problems with constancy in quality, admitting that the highly purified products used with man were prohibitively expensive for veterinary use. It did not help that practitioners disagreed over the ideal type of tuberculin. In 1939, Buxton noted that "one section demands a product which is entirely without action on the skin of negative animals while another complains that in its present form synthetic medium tuberculin does not induce a sufficient reaction". ${ }^{106}$ In an effort to resolve this problem, the Joint Tuberculosis Committee drafted proposals for standardization, drawing on recommendations made by the Bureau of Animal Industry and by Buxton. MAF used this to shape its policy on the desired potency and composition of tuberculin, having become convinced that tuberculin testing offered the best means to tackle bovine tuberculosis in the national herd. ${ }^{107}$

\section{Frustrating Eradication}

Despite MAF's support and the position testing came to occupy in legislation to promote a disease-free milk supply, farmers continued to resist the use of tuberculin. This proved a major barrier to eradication. W L Little, a veterinarian working in Great Yarmouth lamented that he "could not persuade the owner[s]" of local herds "to allow me to test them with tuberculin". ${ }^{108}$ By 1938, only 3 per cent of dairy farmers had had their herds attested, many doing so merely to escape the levies of the Milk Marketing Board as tuberculin tested milk was excluded. ${ }^{109}$ Technical difficulties made farmers distrust tuberculin, notwithstanding efforts by the MRC, ARC and MAF to produce a dependable test and persuade them that

\footnotetext{
${ }^{103}$ Ibid.

${ }^{104}$ PRO: Memorandum, c.1930, MH 58/124.

${ }^{105}$ PRO: Jackson to Beckett, 10 Oct. 1930; minute sheet, 3 Oct.1929, MH 58/124.

${ }^{106}$ Buxton and Glover, op. cit., note 12 above, p. 15 .
}

${ }^{107}$ PRO: 'Provisions applicable to tuberculins intended for testing cattle', 1936, FD 1/4497.

${ }^{108}$ W L Little, 'Cases of tuberculosis among dairy cows', J. comp. Pathol. Ther., 1906, 19: 48.

${ }^{109}$ PRO: NFU Welsh branch, 24 Jan. 1938, MH $55 / 1219$. 


\section{Keir Waddington}

tuberculin was effective. Added to the technical problems with tuberculin, diverse practices and varying degrees of competence among veterinary surgeons also produced mixed results. As one farmer in the 1930s explained, "we have cows pass the test and waste away with tuberculosis within a few weeks". ${ }^{110}$ Under these circumstances, it was felt that the cattledealer and dairy farmer "who trusted to the reaction to give reliable information as to whether his [meat or milk] would be saleable or not naturally lost faith in the test". ${ }^{111}$

Opposition went deeper than a concern with the technical deficiencies of tuberculin. Given the high incidence of the disease, stockowners were unwilling to use tuberculin "on account of the heavy loss to which the anticipated result might subject them". ${ }^{12}$ Compensation remained a difficult issue; one side-stepped by MAF and the Ministry of Health because of the cost implications. Even when compensation was granted under the 1925 Tuberculosis Order, awards were less than the market value of a healthy animal. ${ }^{113}$ Under these conditions, many farmers kept cattle until they showed signs of tuberculosis before selling them to butchers.

Tuberculin testing was expensive in other respects, further discouraging farmers from using it. McFadyean estimated that it cost between $2 \mathrm{~s}$ and $3 \mathrm{~s}$ annually to test a cow; by the 1920 s the cost had risen to 14 s per cow per annum. ${ }^{114}$ Ideally, suitable buildings were required, as well as extra labour; reacting cattle had to be removed and replaced with healthy stock. By the 1920s, this could cost anything up to $£ 35$ per animal in addition to the cost of the test. ${ }^{115}$ These figures made testing uneconomic. A loss of capital in the 1920s, and the onset of depression in the 1930s, saw farmers reluctant or unable to spend money on innovations or new buildings, and it seems that they were not convinced by studies by the Agricultural Economics Research Institute that argued that testing resulted in a higher profit per cow, or by advice manuals that warned of the dire economic consequences if bovine tuberculosis was ignored. ${ }^{116}$ Although the dairy industry was not as depressed as other areas of agriculture, high production costs and low prices made farmers unwilling to shoulder additional expenses in the face of their usually poor capital resources, especially as many had started milk production to escape the depression. Dairy farming was attractive "not because of its inherent profitability ... but because of its rapid rate of turnover and limited capital needs". ${ }^{117}$ Testing threatened this, and with distributors forcing down prices the relative cost of testing rose. ${ }^{118}$

The expense of testing appeared higher in a market where the public was reluctant to pay the premium for TT milk, convinced that "ordinary milk is all right". ${ }^{119}$ Many were confused by differences between "pure" and "clean" milk, and customers for TT milk were scattered. As the Midland Counties Dairy admitted, "the present demand for this grade

\footnotetext{
${ }^{110}$ Dixey, op. cit., note 79 above, pp. 97, 96.

${ }^{111}$ A Porter, 'The preciptin, complement binding and anti-opsonic tests in tuberculous and normal cattle', J. Hyg., 1911, 11: 106.

112 'The danger of tuberculous milk supply', Med. Officer, 2 July 1910, p. 11.

${ }_{113}$ Jordan, op. cit., note 5 above, p. 9.

${ }^{114}$ Royal Commision on Tuberculosis, op. cit., note 31 above, p. 20.

${ }^{115}$ Dixey, op. cit., note 79 above, p. 96.
}

\footnotetext{
${ }^{116}$ Liversage, op. cit., note 87 above, p. 17; A Archer, The stockowner's veterinary aid, London, Lockwood, 1921, p. 132.

${ }^{117}$ David Taylor, 'Growth and structural change in the English dairy industry c.1860-1930', Agric. Hist. Rev., 1987, 35: 61.

${ }_{118}$ Jonathan Brown, Agriculture in England, Manchester University Press, 1987, pp. 92-3.

${ }^{119}$ PRO: Advisory committee on TT milk minutes, 16 Sept. 1938, JV 3/35.
} 


\section{Bovine Tuberculosis and Tuberculin Testing in Britain}

of milk is limited". ${ }^{120}$ The situation was not helped by the Milk Marketing Board and the big distributors. Although both sought to encourage the production of quality milk to improve public confidence in and consumption of milk, they were unenthusiastic about testing and failed to assist farmers keen to take part in MAF's attested herd scheme. ${ }^{121}$

Aside from the expense and doubtful financial return, a mass testing programme was resisted and stockowners were reluctant to comply with even voluntary measures. According to Smith, they "disliked the test because they thought it a bureaucratic intrusion on their farms which upset the cows". ${ }^{122}$ This distrust of state measures as intrusive and unnecessary was sharpened following a policy reversal in 1921 with the repeal of the 1920 Agricultural Act that saw the removal of wartime protectionist measures. ${ }^{123}$ Opposition was reinforced by the fact that the administrative arrangements of the various milk and tuberculosis orders were complex and the attested herd scheme onerous. Procedures for testing were not standardized, despite efforts by the MRC, and resulted in considerable disruption to the farm, which merged with a sense that state intervention in the milk market was forcing up dairy costs. Farmers also complained that "too much is left to the discretion of the vet". For some, "the subsequent visits of the veterinary surgeon resemble a series of nightmares, any one of which may develop into the grim reality that the herd" was infected. ${ }^{124}$

\section{Conclusion}

\section{"To Rid the Country of Tuberculous Cattle"}

Despite technical problems with tuberculin, opposition from farmers, and bureaucratic and professional tensions, by the 1950s it was felt that the only way "that we can hope to rid the country of tuberculous cattle is to use ... [tuberculin] on every bull, cow and calf and eliminate all those who react". ${ }^{125}$ Although the Second World War encouraged a change in the culture of the Ministry of Health and MAF, post-war systems of testing continued to rely on the voluntary co-operation of farmers and the attraction of financial incentives that had been central to attempts to stamp out the disease in the interwar period. Progress in eradicating bovine tuberculosis was thus slow: it was not until 1964 that it became government policy to detect and contain tuberculosis in cattle through routine tuberculin testing, slaughter, compensation, and movement controls. Confidence in tuberculin testing has persisted: as MAFF explained in 1999 tuberculin is "well proven ... gives few false positive results ... and is the standard test used around the world". ${ }^{126}$

Although the practical and widespread adoption of tuberculin testing was delayed, its key role in stamping out bovine tuberculosis was accepted by veterinarians, public health officials and the state by the 1920s. This was because tuberculin was less controversial

\footnotetext{
${ }^{120}$ PRO: Midland counties dairy to NFU, 13 Sept 1937, JV 7/645.

${ }^{121}$ PRO: Representations of the milk marketing board, 29 Sept. 1938, MAF 34/762; PRO: Joint Tuberculosis Committee minutes, 5 Nov. 1937, FD 1/4497.

${ }^{122}$ Smith, op. cit., note 1 above, p. 180.

${ }^{123}$ Edmund Penning-Rowsell, "Who "betrayed" whom? Power and politics in the 1920/21
}

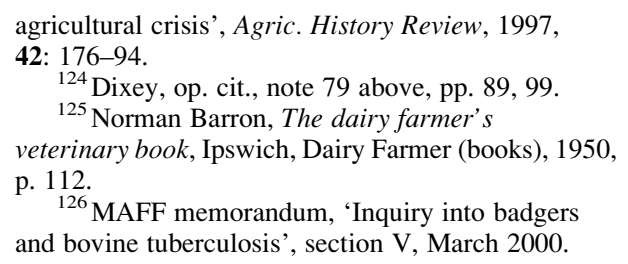




\section{Keir Waddington}

than pasteurization, was cheaper, and encountered less unfavourable business reaction. When linked to voluntary schemes, where the emphasis was on the stockowner, it was included as part of a preventive strategy that favoured minimal state intervention. The voluntary approach adopted cost considerably less than sanatorium care or a full-scale eradication programme, and appealed to the parsimonious nature of the Ministry of Health and MAF. Both were reluctant fully to endorse or fund eradication programmes until the 1960s, seeing them as "impracticable on the ground of expense", a move welcomed by the farming lobby which opposed intervention. Testing therefore fitted with existing practices and notions of voluntary control that dominated measures to promote a clean milk supply. ${ }^{127}$ For MAF, support for voluntary tuberculin testing was a way of protecting the farmer "without unduly depleting the herds of this country", while a search was made for a "vaccine or some other cheap method of control". ${ }^{128}$

Tuberculin had other advantages. Despite evidence that it was unreliable in some cases, it was the most effective mechanism for identifying and controlling bovine tuberculosis. Testing, especially the double intradermal method, was more trustworthy than clinical examination and was broadly welcomed by veterinarians. In addition, tuberculin was more straightforward than bacteriological tests of meat and milk, which were timeconsuming (taking anything up to four weeks), comparatively costly, and required a degree of technical skill and laboratory equipment which was only gradually available. ${ }^{129}$ In comparison, tuberculin was quick, cheap and relatively accurate.

After it was first announced in 1890, tuberculin was soon transformed from a therapy to the diagnostic agent for identifying bovine tuberculosis. Despite resistance from farmers and concerns about its reliability, by the 1920 s tuberculin had become integral to attempts to control the spread of the disease and was officially adopted by MAF and the Ministry of Health in the 1930s. However, the shift towards farming and agricultural concerns in the eradication of bovine tuberculosis served to marginalize the Ministry of Health and place the emphasis on MAF and the farming industry. Both were reluctant to support mass testing on the grounds of expense, while farmers resisted testing. This ensured that while many contemporaries recognized the role tuberculin should play in eradication, measures remained voluntary and linked to market incentives until the $1960 \mathrm{~s}$.

\footnotetext{
${ }^{127}$ Atkins, op. cit., note 10 above, pp. 37-51;

Phillips and French, op. cit., note 10 above,

pp. 371-88.

${ }^{128}$ PRO: Memorandum, 14 Aug. 1931, MAF 35/ 659.
}

\footnotetext{
${ }^{129}$ E R Hiscox and Ursula Starling, 'The use of the fermentation-reductase test for the grading of milk, J. Hyg., 1925, 24: 164-8.
} 